\title{
KONTROL DIRI PADA INDIVIDU YANG ORANG TUANYA BERCERAI DITINJAU DARI PEMAAFAN DAN RELIGIUSITAS
}

\author{
Fairuzatul H. Alamsyah', Ghea Niasgita F. Uzra', Indah D. Rahmalia ${ }^{3}$, \\ Ahmad Rusdi ${ }^{4}$ \\ 1,2,3,4 Master Psikologi, Universitas Islam Indonesia \\ 1alamsyahfairuz93@gmail.com, ${ }^{2}$ gheaniasgita@gmail.com, ${ }^{3}$ dewantiindah@gmail.com, \\ 4ahmad_rusdi@uii.ac.id
}

\begin{abstract}
Abstrak. Individu yang orang tuanya bercerai cenderung mengalami dinamika yang berbeda dengan individu yang orang tuanya memiliki hubungan yang harmonis. Mereka cenderung merasakan pergolakan emosi yang mendalam akibat perceraian kedua orang tuanya yang kemudian berdampak pada bagaimana kemempuan mereka untuk mengontrol dirinya agar tidak terjerumus kepada hal-hal negatif. Beberapa hal yang bisa mendukung kontrol diri dengan baik adalah bagaimana mereka mampu memaafkan peristiwa yang telah tejadi dan mendekatkan diri kepada Allah SWT.Tujuan dari penelitian ini adalah untuk mengetahui hubungan antara pemaafan dan religiusitas terhadap kontrol diri. Subjek dalam penelitian ini berjumlah 37 orang yang memiliki orangtua dengan status bercerai. Analisis data yang digunakan dalam penelitian ini adalah uji regresi berganda dan uji beda. Data dikumpulkan menggunakan skala kontrol diri, skala pemaafan, dan skala religiusitas. Hasil penelitian menunjukkan bahwa terdapat korelasi yang signifikan antara kontrol diripada individu yang orang tuanya bercerai ditinjau dari pemaafan dan religiusitas. Pemaafan memiliki pengaruh langsung terhadap kontrol diri serta memiliki hubungan positif yang signifikan. Religiusitas juga memiliki hubungan dengan kontrol diri, namun hubungan antar keduanya bukanlah hubungan langsung melainkan melalui pemaafan sebagai mediator.
\end{abstract}

Kata Kunci : kontrol diri, pemaafan, religiusitas

Abstract. Individuals whose parents divorce tend to experience different dynamics with individuals whose parents have a harmonious relationship. They tend to feel a deep emotional upheaval due to the divorce of their parents which then affects how they are able to control themselves so as not to fall into negative things. Some things that can support self-control well are how they are able to forgive the events that have occurred and get closer to Allah SWT. The purpose of this study is to determine the relationship between forgiveness and religiosity towards self-control. Subjects in this study amounted to 37 people who have parents with divorced status. Data analysis used in this study is multiple regression test and different test. Data were collected using a scale of selfcontrol, forgiveness scale, and scale of religiosity. The results showed that there was a significant correlation between controls in the individual whose parents divorced in terms of forgiveness and religiosity. Forgiveness has a direct influence on self-control and has a significant positive relationship. Religiosity also has a relationship with selfcontrol, but the relationship between the two is not a direct relationship but through forgiveness as a mediator.

Keyword : self-control, forgiveness, religiosity 
Bennet (Dewi, 2006) menyatakan bahwa sebuah perceraian merupakan sebuah hubungan yang diputuskan setalah ditetapkan oleh negara (secara legal). Perceraian yang terjadi pada orang tua tentunya memberi dampak bagi kehidupan anak-anaknya, salah satunya berdampak pada kehidupan anak saat berada dalam tahap dewasa awal. Fase dewasa awal merupakan masa-masa dimana individu akan berinteraksi dengan lingkungan yang baru, lebih emosional, dan banyak nilai yang berubah (Hurlock, 2001). Anak yang orang tuanya bercerai lebih merasa sensitif dan lebih mudah marah sehingga meningkatkan resiko stres di usis muda (Maleck \& Papp, 2015). Dewasa awal yang memiliki background kedua orang tuanya berkonflik, akan memiliki pandangan yang lebih negatif, mengalami kesulitan dalam berkomunikasi, dan melakukan agresi fisik dan verbal dalam hubungan romantis (Maleck \& Papp, 2015).

Penelitian yang dilakukan oleh Mahl (2000) menemukan bahwa perceraian orang tua dapat berdampak pada hubungan sosial dewasa awal serta ditemukan bahwa kebanyakan dewasa awal akan menyesuaiakan atau bahkan meniru dnegan baik perceraian orang tuanya. Selain itu, perceraian orang tua dapat mengakibatkan berkurangnya kesejahteraan sosial, psikologis, dan fisik anak serta dapat juga mengurangi komitmen untuk menjalani pernikahan (Knox, Zusman, dan DeCuzzi, 2004). Pada kenyataannya banyak perceraian yang tidak hanya memberikan dampak negatif tetapi juga positif kepada anak korban perceraian terutama pada anak. Pada kenyataanya, seperti penelitian yang dilakukan oleh Harsanti dan Verasari (2013), menunjukkan bahwa subjek dengan keluarga bercerai telah melakukan berbagai hal yang negatif seperti menggunakan narkoba, minum-minuman keras, melakukan seks bebas, melakukan perusakan tempat umum dan suka berkelahi. Perceraian juga dapat memberikan dampak positf ketika anak dapat menyikapinya dengan baik (Moko dalam Hakim dan Rahmawati, 2015).

Mengingat dampak negatif jangka panjang dari perceraian yang dilakukan orang tua sangat mempengaruhi kehidupan anak, sudah seharusnya individu-individu tersebut memiliki kontrol diri yang kuat agar mereka mampu menjalani kehidupan sama halnya dengan individu-individu yang orang tuanya tidak bercerai. Yaben (2009) menambahkan bahwa perceraian berdampak negatif pada hampir seluruh aspek kehidupan. Ghufron dan Rini (Nurhayati, 2015), kontrol diri diartikan sebagai suatu aktivitas pengendalian tingkah laku. Ketika individu tidak dapat mengontrol diri, individu tersebut akan sulit untuk menentukan kemana mereka akan pergi. Seperti yang dikatakan oleh DeWall, Baumeister, \& Masicampo (Evans dkk, 2011) individu yang tidak dapat mengontrol dirinya akan merasa kesusahan dalam menentukan pilihannya. Ayat alquran mengatakan bahwa :

"Sesungguhnya orang-orang yang beriman dan berhijrah serta berjihad dengan harta dan jiwanya pada jalan Allah dan orang-orang yang memberikan tempat kediaman dan pertolongan (kepada orang-orang muhajirin), mereka itu satu sama lain lindung-melindungi. Dan (terhadap) orang-orang yang beriman, tetapi belum berhijrah, maka tidak ada kewajiban sedikitpun atasmu melindungi mereka, sebelum mereka berhijrah. (Akan tetapi) jika mereka meminta pertolongan kepadamu dalam (urusan pembelaan) agama, maka kamu wajib memberikan pertolongan kecuali terhadap kaum yang telah ada perjanjian antara kamu dengan mereka. Dan Allah Maha Melihat apa yang kamu kerjakan.” QS. Al Anfal (8): 72 
Ayat ini mengandung makna bahwa Kaum Muhajirin dan Anshar telah memberikan teladan dalam mujahadah an-nafs. Secara bahasa mujahadah artinya bersungguhsungguh, sedangkan an-nafs artinya jiwa, nafsu, diri. Jadi mujahadah an-nafs artinya perjuangan sungguh-sungguh melawan hawa nafsu atau bersungguh-sungguh menghindari perbuatan yang melanggar hukum-hukum Allah SWT. Menurut bahasa Indonesia, mujahadah an-nafs disebut dengan kontrol diri. Kontrol diri merupakan salah satu perilaku terpuji yang harus dimiliki setiap muslim. Individu yang kontrol dirinya rendah tidak mampu mengatur dan mengarahkan perilakunya.

Kontrol diri dipengaruhi oleh kontrol emosi. Kontrol emosi yang sehat dapat diperoleh bila individu memiliki kekuatan ego, yaitu sesuatu kemampuan untuk menahan diri dari tindakan luapan emosi. Oleh sebab itu salah satu hal yang dapat dilakukan untuk meningkatkan kontrol diri individu adalah dengan melakukan pemaafan dan meningkatkan religiusitas. Fakhruroji (2008) menyatakan, memaafkan tidaklah hanya menjadikan kondisi mental kita yang lebih baik tetapi juga kondisi fisik, sebab tubuh manusia membutuhkan keseimbangan hormon yang dapat terganggu ketika dalam keadaan stres, depresi, marah, ataupun sedih, dan sebagainya. Hormon yang tidak stabil tersebut mengarahkan individu untuk bertindak destruktif yang dapat merugikan diri sendiri ataupun orang lain. Ayat Al-Quran berbunyi :

"Jika kamu melahirkan sesuatu kebaikan atau menyembunyikan atau memaafkan sesuatu kesalahan (orang lain), maka sesungguhnya Allah Maha Pema 'af lagi Maha Kuasa.” (QS. An-Nisa : 149)

"Tetapi orang yang bersabar dan memaafkan, sesungguhnya (perbuatan) yang demikian itu termasuk hal-hal yang diutamakan.” (QS. Asy-Syura : 43)

Ayat di atas menyatakan bahwa kita sebagai umat muslim sudah sewajarnya memberi maaf terhadap kesalahan yang dilakukan oranglain terhadap diri kita. Ancok dan Suroso (2005) menyatakan bahwa religiustas juga ikut bertanggungjawab terhadap norma-norma social sehingga religiusitas mampu menyeleksi kaidah-kaidah social dengan menguatkan kaidah yang baik dan menolak kaidah yang buruk.Penelitian berjudul, "mengobati luka anak korban perceraian melalui pemaafan" yang dilakukan oleh Hikmah (2015) menunjukkan bahwa pemaafan sangat dibutuhkan untuk mengelola dan menanggulangi distres yang dirasakan.

Berdasarkan penjelasan di atas, dapat di lihat bahwa tujuan dari penelitian ini adalah untuk mengetahui adanya hubungan antara pemaafan dan religiusitas terhadap kontrol diri pada individu yang orang tuanya bercerai. Hipotesis yang diajukan peneliti dalam penelitian ini adalah terdapat hubungan yang signifikan antara pemaafan dan religiusitas terhadap kontrol diri pada individu yang orang tuanya bercerai.

\section{METODE}

Subjek dalam penelitian ini merupakan beberapa individu yang tergabung dalam komunitas $\mathrm{X}$, yaitu suatu komunitas yang mewadahi para individu yang memiliki orang tua dengan status bercerai untuk saling berinteraksi dan bertukar cerita. Komuntas ini berdomisili di Yogyakarta. Populasi subjek penelitian ini berjumlah kurang lebih 104 orang. Sample yang diambil sebanyak kurang lebih 37 orang yang terdiri dari 14 laki-laki dan 23 perempuan. 
Pengambilan sampel subjek dilakukan menggunakan non probability sampling yaitu quota sampling, yang artinya teknik sampling yang menentukan jumlah sampel dari populasi yang memiliki ciri tertentu sampai jumlah kuota (jatah) yang diinginkan. Dalam penelitian ini, peneliti mengambil sampel sebanyak 20-25\% dari jumlah populasi sesuai dengan pendapat Arikunto (2002).

Selain itu, peneliti juga menambahkan beberapa karakteristik untuk subjek yang digunakan dalam penelitian ini, yaitu individu yang memiliki orang tua bercerai, berada pada usia dewasa awal (18-28 tahun), beragama islam dan belum menikah.

Metode pengumpulan data dalam penelitian ini menggunakan tiga skala, yaitu skala kontrol diri, skala pemaafan, dan skala religiusitas. Skala kontrol diri terdiri dari 30 aitem yang disusun oleh Nashori (2004)yang mengacu kepada teori Burger (1989)dengan memanfaatkan sejumlah aitem yang digunakan oleh Ghozali (2005) dengan reliabilitas sebesar 0.793. Pemaafan diukur menggunakan skala yang disusun sendiri oleh peneliti yang mengacu pada teori Nashori (2014) yang terdiri dari 19 aitem dengan reliabilitas sebesar 0.896 .

Sedangkan religiusitas diukur menggunakan skala yang disusun oleh Nashori (2016) yang terdiri dari 47 aitem berupa skala religiusitas 1 dan skala religiusitas 2 dengan reliabilitas sebesar 0.912. Skala ini didasarkan pada pendapat Ancok dan Suroso (2005) serta Nashori dan Mucharam (2002) yang telah melakukan verifikasi terhadap pandangan Glock dan Stark (Dister, 1988). Skala Religiusitas 1 akan mengukur 4 dimensi, yaitu akidah, ibadah, akhlak, dan ihsan. Sementara Skala Religiositas 2 akan mengukur dimensi ilmu agama.

Data dari penelitian ini dianalisis menggunakan uji asumsi yang terdiri dari uji normalitas, uji linearitas, dan uji multikolinearitas. Ketiga uji asumsi tersebut merupakan syarat untuk melakukan uji hipotesis menggunakan analisis regresi. Analisis regresi merupakan jenis uji statistika yang digunakan untuk melihat daya prediksi variabel independen (prediktor) terhadap variabel dependen (kriterium) dimana variabel independen jumlahnya lebih dari satu. Proses analisis data dilakukan menggunakan program IBM SPSS Statistics 23.0.

\section{HASIL}

Penelitian ini melibatkan 35 orang subjek dengan rincian 14orang laki-laki dan 21 orang perempuan. Berdasarkan hasil analisis deskriptif diperoleh bahwa nilai rata-rata pada kontrol diri sebesar 71,5 $(S D=12,1)$, rata-rata pada pemaafan sebesar 78,8 $(S D=11,2)$, dan rata-rata pada religiusitas sebesar $-0,3(S D=20,3)$. Berdasarkan hasil analisis deskriptif menunjukkan bahwa sebanyak 6 orang memiliki kemampuan kontrol diri yang baik, 22 orang tergolong cukup baik, dan 7 orang tergolong kurang baik. Dilihat dari segi pemaafannya, sebanyak 5 orang memiliki tingkat pemaafan yang rendah, 23 orang memiliki tingkat pemaafan yang tergolong sedang, dan 7orang memiliki tingkat pemaafan yang tergolong tinggi. Hasil analisis deskriptif lainnya menunjukkan bahwa sebanyak 3 orang memiliki tingkat religiusitas yang tergolong rendah, 26 orang tergolong sedang, dan 6 orang tergolong tinggi (lihat tabel berikut). 
Tabel 1. Kategorisasi

\begin{tabular}{lcccccc}
\hline & \multicolumn{2}{c}{ Kontrol diri } & Pemaafan & \multicolumn{2}{c}{ Religiusitas } \\
& $\mathrm{N}$ & $\%$ & $\mathrm{~N}$ & $\%$ & $\mathrm{~N}$ & $\%$ \\
\hline Baik/tinggi & 6 & 17.1 & 7 & 20.0 & 6 & 17.1 \\
Cukup/sedang & 22 & 62.9 & 23 & 65.7 & 26 & 74.3 \\
Kurang baik/rendah & 7 & 20.0 & 5 & 4.3 & 3 & 8.6 \\
\hline
\end{tabular}

Berdasarkan hasil uji normalitas menunjukkan bahwa distribusi data dari ketiga variabel penelitian adalah normal.Hal ini terlihat dari nilai signifikansi pada variabel kontrol dirisebesar $0.200(\mathrm{p}>0.05)$, pemaafan sebesar 0.071 ( $\mathrm{p}>0.05)$, dan variabel religiusitas sebesar 0.055 ( $\mathrm{p}>0.05)$. Selain itu, korelasi antara kontrol diri dan pemaafan menunjukkan nilai signifikansi sebesar 0.002 ( $\mathrm{p}<0.05$ ) dengan $F=14,6$ atau linear. Kemudian, korelasi antara kontrol diridan religiusitas menunjukkan nilai signifikansi sebesar $0.131(\mathrm{p}>0.05)$ dengan $F=6,2$ atau tidak linear.

Berdasarkan hasil analisis menunjukkan bahwa data yang digunakan tidak mengalami multikolinearitas. Hal ini dapat dilihat dari masing-masing nilai tolerance sebesar 0.63 (> 0.1) dan nilai VIF sebesar 1.59 (<10). Selain itu, analisis lain juga menunjukkan bahwa tidak terjadi autokorelasi yang ditunjukkan dari nilai pada Durbin-Watson $=2,10(\mathrm{dU}=$ 1,58). Berdasarkan hasil uji korelasi menggunakan pearson correlation, nilai $\mathrm{p}=0.000($ $\mathrm{p}<0.01$ ) untuk kontrol diri dan pemaafan. Hal ini menunjukkan bahwa terdapat korelasi yang signifikan antara kontrol diri pada individu yang orang tuanya bercerai ditinjau dari pemaafan. Begitu pula jika ditinjau dari religiusitas, kontrol diri memiliki korelasi dengan nilai $\mathrm{p}=0,008(\mathrm{p}<0,01)$. Jika ditinjau secara langsung melalui keduanya, juga terdapat hubungan langsung antara variabel pemaafan dan religiusitas terhadap kontrol diri dengan nilai $\mathrm{p}=0,001(\mathrm{p}<0,01)$ dan nilai $\mathrm{R}^{2}=0,346$.

Jika dilihat hubungan langsung antar variabel independen terhadap variabel dependen, didapatkan hasil bahwa hanya variabel pemaafan yang memiliki pengaruh langsung terhadap kontrol diri serta terdapat hubungan positif yang signifikan antara kontrol diri terhadap pemaafanpada individu yang orang tuanya bercerai. Hal ini dapat dilihat dengan nilai koefisien $b$ adalah sebesar $0582\left(\beta_{b}=0,539\right)$ dan nilai koefisien $c$ ' adalah sebesar $0,045\left(\beta_{\mathrm{c}^{\prime}}=0,76\right)$. Nilai $\mathrm{t} b=1,664$ dan signifikansi $\mathrm{p}<0,05$, sedangkan nilai $\mathrm{t} c^{\prime}=0,421 \mathrm{dan}$ signifikansi $p>0,05$. Dengan demikian variabel peemaafan secara signifikan mempengaruhi..

Tabel 2. Hasil Uji Peran Mediator

Coefficients $^{\mathrm{a}}$

\begin{tabular}{lcccccc}
\hline & \multicolumn{2}{c}{ Unstandardized Coefficients } & $\begin{array}{l}\text { Standardized } \\
\text { Coefficients }\end{array}$ & & & \\
\cline { 2 - 5 } Model & B & Std. Error & Beta & t & Sig. \\
\hline (Constant) & 25.691 & 15.443 & & 1.664 & .106 \\
\hline PEMAAFAN & .582 & .195 & .539 & 2.989 & .005 \\
\hline RELIGIUSITAS & .045 & .108 & .076 & .421 & .676 \\
\hline
\end{tabular}

a. Dependent Variable: KONTROL_DIRI 


\section{DISKUSI}

Berdasarkan hasil analisis data yang dilakukan, menunjukan bahwa terdapat hubungan yang signifikan dan positif antara pemaafan dan religiusitas terhadap kontrol diri pada individu yang orang tuanya bercerai atau dengan kata lain hipotesis diterima dengan sumbangan sebesar 34,6\% dan dipengaruhi oleh variabel lain diluar penelitian sebesar $65,4 \%$. Kontrol diri sendiri merupakan sikap dimana seseorang mengelola dirinya agar perilaku yang muncul adalah perilaku positif. Semakin tinggi tingkat pemaafan individu, maka kontrol dirinya juga akan semakin baik.

Ketika seseorang mengalami permasalahan yang tidak dapat dikontrol, individu akan cenderung mengeluarkan perilaku yang negatif. Permasalahan yang dimaksud dalam hal ini adalah pereraian orangtua. Prihatiningsih (2015) mengatakan bahwa seorang individu dengan kontrol diri yang rendah cenderung menyalurkan kerinduannya terhadap orang tuanya dengan melakukan kenakalan remaja seperti tawuran dan sebagainya. Diriwayatkan dari Abi Hurairah ra. bahwa Rasulullah bersabda:

"Orang yang perkasa bukanlah orang yang menang dalam perkelahian, tetapi orang yang perkasa adalah orang yang mengendalikan dirinya ketika marah."(H.R. Bukhari dan Muslim)

Hadist di atas bermaksud bahwa setiap individu harus mampu untuk mengendalikan dirinya sendiri agar tidak muncul perilaku yang merugikan bagi orang-orang disekitarnya. Maka dari itu, kontrol diri yang baik sangat diperlukan. Ada beberapa hal yang mempengaruhi terbentuknya kontrol diri yang baik pada seorang individu. Hal tersebut bisa berasal dari luar maupun dari dalam indivdu tersebut. Pada penelitian ini, terdapat dua faktor yang mempengaruhi seorang individu mempunyai kontrol diri yang baik. Faktor tersebut ialah pemaafan dan religiusitas, dimana kedua faktor tersebut berpengaruh dalam meningkatkan kontrol diri seorang individu dengan orangtua yang bercerai.

Kontrol diri dapat ditingkatkan dalam diri individu dengan berbagai cara. Salah satunya adalah dengan meningkatkan religiusitas serta melakukan pemaafan.Sejalan dengan penelitian yang dilakukan oleh Fakhruroji (2008) yang menyatakan bahwa memaafkan tidaklah hanya menjadikan kondisi mental kita yang lebih baik tetapi juga kondisi fisik, sebab tubuh manusia membutuhkan keseimbangan hormon yang dapat terganggu ketika dalam keadaan stres, depresi, marah, ataupun sedih, dan sebagainya. Kehidupan religius atau keagamaan menurut Najati (Irawati, Subandi, Kumolohadi, 2011) dapat membantu manusia dalam menurunkan kecemasan, kegelisahan, dan ketegangan.

Hormon yang tidak stabil tersebut mengarahkan individu untuk bertindak destruktif yang dapat merugikan diri sendiri ataupun orang lain. Allah Subhanahu wa Ta'ala berfirman

"Dan balasan suatu kejahatan adalah kejahatan yang serupa. Barangsiapa memaafkan dan berbuat baik maka pahalanya atas (tanggungan) Allah. Sesungguhnya Dia tidak menyukai orang-orang yang zalim.” (Asy-Syura: 40) Ayat tersebut menyatakan bahwa, kita sebagai umat muslim hendaknya saling memaafkan dan tidak menyimpan dendam. Hal ini serupa dengan yang diungkapkan oleh Enright dan Coyle (1998) bahwa forgivenesssebagai kesediaan untuk meninggalkan hak kebencian seseorang, penilaian negatif, dan perilaku acuh tak acuh terhadap seseorang yang menyakiti kita, bahkan mendorong kasih sayang, kemurahan hati. Memaafkan jugasangatlah penting, sebab dengan memaafkan maka pikiran-pikiran negatif dapat 
terlepaskan dan hubungan dengan individu lain juga dapat terjalin dengan baik, serta silaturahmi yang sempat terputus dapat terjalin kembali.

Ada kalanya kita sulit untuk memaafkan kesalahan individu lain, bahkan kesalahan individu-individu terdekat kita sekalipun. tanpa disadari, ketika kita merasa benci, marah, dendam, dan sebagainya secara terus menerus sebenarnya kita sedang menyiksa diri kita secara tidak langsung. Hal ini terjadi karena dengan perasaan tersebut kita akan memberikan stres pada diri kita. Hasil penelitian Tai Mui(Annisa dan Marettih, 2016) yang menunjukkan bahwa ketikaindividu mendapatkan penjelasan terhadap kesalahankesalahan orang lain yang berbuat salah, maka emosi negatif individu akan berubah menjadi rasaprihatin, sehingga individu akan mencobamemahami dan berfikiran positifterhadap kesalahan orang lain dan mendorongindividu untuk memaafkan oranglain yang telah berbuat salah.

Dwityaputri dan Sakti (2015) telah melakukan penelitian dengan hasil berupa koefisien korelasi $r x y=0.70(p<0,05)$, yang berarti ada hubungan positif yang signifikan antara regulasi emosi dengan forgiveness. Penelitian yang dilakukan oleh Rahmandani (2015) juga menemukan bahwa terdapat hubungan antara pemaafan dan aspek dari kontrol diri dimana semakin tinggi pemaafan semakin tinggi pula kontrol diri yang dimiliki. Meski dengan memberi maaf anak tetap tidak dapat merubah peristiwa yang sudah terjadi, ia bisa merubah persepsi, emosi, asosiasi mental, dan pemahaman akan makna dari peristiwa yang telah dialaminya (Worthington, dalam Setyawan 2007).

Saat seseorang memaafkan, tingkat hilangnya pengendalian diri akan mengalami penurunan, hal ini menyebabkan seseorang menghentikan dorongan untuk balas dendam (Worthnington dkk., 2005). Pada penelitian ini juga, terlihat tingkatan-tingkatan yang dimiliki oleh setiap responden dalam kategorisasi. Responden dengan kontrol diri tinggi sebesar $13,5 \%$, cukup $73 \%$, serta rendah $13,5 \%$. Variabel lainnya yaitu pemaafan dalam kategori tinggi sebesar $83,8 \%$, sedang 2,7\%, dan rendah sebesar 13,5\%. Pada variabel religius tinggi sebesar $21,6 \%$, sedang sebesar $62,2 \%$, dan rendah sebesar $16,2 \%$. Dari data tersebut telihat bahwa sebagian besar responden berada dalam kategori sedang dimana kontrol diri, religiusitas, serta pemaafan yang dimiliki dapat dikatakan sudah cukup bagus.

Variabel lain yang berpengaruh dalam peningkatan kontrol diri yaitu religiusitas. Penelitian yang dilakukan oleh Aviyah dan Farid (2014) menunjukan bahwa ketika seorang individu memiliki religiusitas yang baik, maka akan semakin kecil kecenderungan untuk melakukan tindakan yang negatif. Begitu pula dengan kontrol diri dimana seseorang memiliki kontrol diri yang baik, maka individu tersebut kemungkinan kecil akan melakukan tindakan yang merugikan dirinya sendiri maupun lingkungannya. Bunyi surat al-Baqarah (2) ayat 208 sebagai berikut:

"Hai orang-orang yang beriman, masuklah kamu ke dalam Islam secara keseluruhannya, dan janganlah kamu turut langkah-langkah setan. Sesungguhnya setan itu musuh yang nyata bagimu"

Penelitian lain yang menghubungkan antara religiusitas dan kontrol diri adalah penelitian yang dilakukan oleh McCullough dan Willoughby (2009). Penelitian tersebut menyebutkan bahwa religiusitas itu dapat mempengaruhi kontrol diri, sebab dalam religiusitas terdapat norma-norma yang mengatur kehidupan manusia. 
Peneitian ini juga tidak terlepas dari berbgai kelemahan didalamnya, seperti penggunaan litertur yag masih terbatas, pengisan skalaa oeh koresponden yang tidak dalam pengawasan peneliti, jumlah subjek ang terbilang sedikit, serta jumlah aaitem dalam sakala yang terbilang cukup banyak. Untuk itu, penelitian selanjutnya dihrapkan untk memperhatikan hal-hal yang telah disebutkan di atas.

\section{SIMPULAN DAN IMPLIKASI}

Berdasarkan hasil penelitian, dapat disimpulkan bahwa terdapat korelasi yang signifikan antara kontrol diripada individu yang orang tuanya bercerai ditinjau dari pemaafan dan religiusitas, yang artinya pemaafan dan religiusitas memiliki keterikatan yang berpengaruh pada kontrol diri individu yang orang tuanya bercerai. Hasil penelitian juga menunjukkan bahwa pemaafan memiliki pengaruh langsung terhadap kontrol diri serta terdapat hubungan positif yang signifikan antara kontrol diri terhadap pemaafan pada individu yang orang tuanya bercerai. Hal ini menunjukkan semakin tinggi pemaafan maka semakin tinggi kontrol diri. Religiusitas juga memiliki hubungan dengan kontrol diri, namun hubungan antar keduanya bukanlah hubungan langsung melainkan melalui pemaafan sebagai mediator.

Saran bagi individu dengan kondisi keluarga bercerai, hendaknya meningkatkan pemaafan dan religiusitas yang dimiliki agar tetap mempunyai kontrol diri yang baik. Kontrol diri yang baik akan berpengaruh terhadap bagaimana individu dapat menjalani kehidupannya sehari-hari. Individu juga diharapkan untuk dapat memaafkan segala bentuk perlakuan tidak menyenangkan yang tertuju pada dirinya dengan kontrol diri yang baik sehingga tidak menimbulkan perilaku yang negatif.

Saran bagi komunitas yang bersangkutan, hendaknya komunitas mendata setiap anggotanya dan serius dalam mengelola administrasi yang ada. Komunitas juga disarankan membuat pertemuan beberapa kali sesuai jadwal agar setiap anggota yang ada dapat bertukar pikiran dan mampu untuk mengontrol perilaku negatif yang muncul. Komunitas juga dapat membuat beberapa kegiatan seminar edukasi maupun pelatihan untuk membantu anggota komunitas dalam rangka menigkatkan kontrol diri, religiusitas maupun pemaafan.

Saran lainnya ditujukan untuk peneliti selanjutnya. Peneliti selanjutnya diharapkan agar ketika mengambil data sebaiknya secara langsung dengan harapan peneliti dapat mengetahui kondisi yang dijalani oleh individu dan untuk mendapatkan data tambahan melalui wawancara singkat. Diharapkan juga agar peneliti selanjutnya tertarik untuk meneliti bagaimana pemaafan berhubungan dengan setiap variabel dari kehidupan manusia itu sendiri, misalnya ketenangan hati, kebersyukuran, serta psychological wellbeing.

Jauh dari pada itu, penelitian ini sendiri masih terdapat beberapa kelemahan sehingga dibutuhkan penelitian-penelitian selanjutnya yang dapat mendukung hipotesis yang diajukan dalam penelitian ini. Keterbatasan penelitian ini meliputi keterbatasan waktu pengambilan data yang cukup singkat. Hal ini berpengaruh terhadap pemilihan metode sampling dari peneliti yang cukup kesulitan dalam mengupayakan teknik probability sampling dikarenakan keterbatasan waktu dan adminitrasi. Selanjutnya adalah penyebaran alat ukur yang menggunakan google doc hal ini terkait administrasi dari 
komunitas itu sendiri dan ketersediaan anggota yang cukup sulit untuk ditemui secara langsung, satu per satu. Akibatnya adalah pengisian kuesioner yang tidak bisa diawasi langsung dan kemungkinan error jadi lebih banyak. Terakhir, keterbatasan penelitian ini terdapat pada referensi, yakni kurangnya referensi penelitian terdahulu untuk variabel ketenangan hati. Untuk itu, penelitian selanjutnya dihrapkan untk memperhatikan hal-hal yang telah disebutkan di atas.

\section{REFERENSI}

Al-Qur'an dan Terjemahan. (2000). Kerajaan Saudi Arabia: Al- Mujamma' (Lembaga Percetakan Al-Qur'an Raja Fahd).

Ancok, D. \&Suroso, F. N. (2005). Psikologi Islam : Solusi Islam Atas Problem-Problem Psikologi. Yogyakarta: Pustaka Pelajar.

Annisa, R. \&Marettih, A. K. E. (2016). Empathy Care Training Untuk Meningkatkan Perilaku Memaafkan Pada Remaja Akhir. Jurnal Intervensi Psikologi Vol. 8 No. 2 Desember 2016.

Arikunto,S. (2002). Metodologi Penelitian. Penerbit PT. Rineka Cipta. Jakarta.

Aviyah, E \&Farid, M. (2014). Religiusitas, Kontrol Diri dan Kenakalan Remaja. Pesona Jurnal Indonesiai, 3 (2), 126-129.

Burger, J.M. (1989). NegativeReaction: To IncreaseIn Perceived Personal Control. Journal Of Personality And Psychology.

Dewi, M. (2006). Gambaran Memaafkan Pada Remaja Yang Orang Tuanya Bercerai. Jurnal Psikologi, 4 (1).

Dwiyaputri, Y. K., \&Sakti, H. (2015). Hubungan antara Regulasi Emosi Dengan Forgiveness pada Siswa Di SMA Islam Cikal Harapan BSD-Tangerang Selatan. Jurnal Empati, 4(2), 20-25.

Dister, N.S. (1988). Psikologi Agama. Yogyakarta : Kanisius.

Enright, R.D., \&Coyle, C.T. (1998). Researching The Process Model Of Forgiveness Within Psychological Interventions. Dalam Worthington, E.L. (Ed). Dimensions Of Forgiveness. Hal. 139-161. USA: Templeton Foundation Press.

Evans, A. M., Dillon, K. D., Goldin, G. \&Krueger, J. I. (2011). Trust And Self-Control: The Moderating Role Of The Default. Judgement And Decision Making. 6(7), 697705.

Fakhruroji, M. (2008). Total Forgiveness. Bandung: Mizani.

Ghozali, I., 2005. Aplikasi Analisis Multivariate dengan Program SPSS, Edisi Ketiga. BP-Universitas Diponegoro, Semarang. 
Hadriami, E. (2008). Pemaafaan dalam Kaidah Kerukunan Hidup Orang Jawa. Psikodimensia. Vol. 07 Januari-Juni.

Hakim, S. N., \&Rahmawati, B. A. (2015). Strategi Coping dalam Menghadapi Permasalahan Akademik Pada Remaja yang Orang Tuanya Mengalami Perceraian. Psychology Forum UMM, Isbn: 978-979-796-324-8

Harsanti, I., \&Verasari, G. D. (2013). Kenakalan Pada Remaja yang Mengalami Perceraian Orangtua. Proceeding PESAT (Psikologi, Ekonomi, Sastra, Arsitektur, Dan Teknik Sipil). Vol.5

Hikmah, S. (2015). Mengobati Luka Anak Korban Perceraian Melalui Pemaafan. SAWWA, $10(2)$.

Hartini, S. M. (2016). Hubungan Religiusitas dan Pola Asuh Terhadap Perilaku Moral Remaja. Skripsi, 1-162.

Hurlock, E. B. (2001). Developmental Psychology Fourth Edition.United States Of America: Mcgraw-Hill, Inc.

Irawati, D., Subandi., \&Kumolohadi, R. (2011). Terapi Kognitif Perilaku Religius Untuk Menurunkan Kecemasan Terhadap Kematian Pada Penderita Hiv/Aids. Jurnal Intervensi Psikologi, 3(2).

Knox, D., Zusman, M., DeCuzzi, A. (2004). The Effect Of Parental Divorce On Relationship With Parents And Romantic Partners Of College Students. College Student Journal 38, 4; Proquest Psychology Journals, 597-601.

Mahl, D.A. (2000). The Influence Of Parental Divorce On The Romantics Relationship Beliefs Of Young Adults. Dissertation Doctor Of Philosophy On University Of TexasAt Austin: Bell \&Howell Information Of Learning.

Maleck, S \&Papp, L.M. (2015). Childhood Risky Family Environtments And Romantic Relationship Functioning Among Yong Adult Dating Couples. Journal Of Family Issues, 36 (5), 567-588.

Mccullough, M.E., \&Willoughby, B. L. B. (2009). Religion, Self-Regulation, And SelfControl: Association, Explanation, And Implications. Psychological Bulletin, 135 (1), 69-93.

Nashori, H. F. 2004. "Proses Kreatif Penulis Muslim”. Laporan Penelitian. Yogyakarta: LP UII.

Nashori, F. (2014). Psikologi Pemaafan: Memahami Pemaafan Etnis Jawa. Yogyakarta: Safiria Insania Press.

Nashori, F. (2016). Pemaafan pada Etnis Madura (Pengaruh Religiositas dan Keterikatan Interpersonal Melalui Sifat Kebaikan Hati dan Sifat Neurotisisme terhadap Pemaafan) . Psikologi Masyarakat, 1-60. 
Nashori, F . \&Mucharam, R.D. (2002). Mengembangkan Kreativitas dalam Perspektif Psikologi Islam.Yogyakarta: Menara Kudus

Nurhayati. (2015). Hubungan Kontrol Diri dengan Prokrastinasi Kerja Pada Pegawai PTPLN (Persero) Rayon Samarinda Ilir. Ejournal Psikologi. 3(2), 492-503.

Prihatiningsih, S. (2015). Journal Juvenile Delinquency (Juvenile Delinquency) In Adolescent Victims Son Divorce Of Parents.

Rahmandani, A. (2015). Pemaafan dan Aspek Kognitif Dari Stres Pada Mahasiswi Jurusan Kebidanan Tingkat Dua. Jurnal Psikologi Undip, 4(2), 118-128.

Safitri, A.M. (2017). Proses dan Faktor Yang Mempengaruhi Perilaku Memaafkan Pada Remaja Broken Home. Psikoborneo, 2017, 5 (1) : 152 - 161. ISSN 2477-2674 (Online), ISSN 2477-2666.

Sakti, Dkk. (2012). Perilaku Memaafkan Istri Pada Ketidaksetiaan Suami. Jurnal Psikologi. Volume 01, Nomor 01, Tahun 2012. Fakultas Psikologi Universitas Diponegoro.

Setyawan, I. (2007). Membangun Pemaafan Pada Anak Korban Perceraian. Dipresentasikan Pada Konferensi Nasional I IPK - HIMPSI : Stress Management Dalam Berbagai Setting Kehidupan, Bandung 2-3 Februari 2007

Tri \& Faturohman. (2009). Psikologi Pemaafan. Jurnal Psikologi, 25, 1-11.

Worthington Jr, E.L., Van Cyan, W.C., Lerner,A.J., \&Scherer, M. (2005) Forgiveness In Health Research And Medical Practice. Explore, J (3), 169-176.

Yaben, S. Y. (2009). Forgiveness, Attachment, And Divorce. Journal Divorce AndRemarriage, 50(4), 282-294.

Yusuf, U. \& Patrisia, R. (2011). Pengaruh Terapi Kognitif Perilaku Terhadap Peningkatan Kontrol Diri Pada Residivis. Jurnal Intervensi Psikologi, 3(2). 